\title{
NUMERICAL SIMULATION AND EXPERIMENTAL OBSERVATIONS OF CONFINED BUBBLE GROWTH DURING FLOW BOILING IN A MICROCHANNEL WITH RECTANGULAR CROSS- SECTION OF HIGH ASPECT RATIO
}

\author{
Y.Q. Zu, \\ School of the Built Environment, \\ University of Nottingham, UK \\ laxyz13@nottingham.ac.uk
}

\author{
S. Gedupudi \\ School of Engineering \& Design, \\ Brunel University, UK \\ Sateesh.Gedupudi@brunel.ac.uk
}

\author{
Y.Y Yan \\ School of the Built Environment, \\ University of Nottingham, UK \\ yuying.yan@nottingham.ac.uk
}

\author{
T.G. Karayiannis \\ School of Engineering \& Design, \\ Brunel University, UK \\ tassos.karayiannis@brunel.ac.uk
}

\author{
D.B.R. Kenning \\ School of Engineering \& Design, \\ Brunel University, UK \\ David.Kenning@brunel.ac.uk
}

\begin{abstract}
Bubble nucleation and growth to confinement during flow boiling in microchannels lead to high heat transfer coefficients. They may also create pressure fluctuations that change the superheat driving evaporation and cause flow reversals that promote transient dry-out and uneven distribution of flow between parallel channels. The work described in this paper is part of a programme to develop models for these processes that will aid the design of evaporative cooling systems for devices operating at high heat fluxes.

Video observations of water boiling in a single copper channel of rectangular cross-section, $0.38 \times 1.6 \mathrm{~mm}$ and a heated length $40 \mathrm{~mm}$, were performed. The top side of the channel was a glass window. Results are presented for a heat flux, averaged over the area of the three metal sides, of 210 and $173 \mathrm{~W} / \mathrm{m}^{2} \mathrm{~K}$ for incompressible and compressible inlet flow conditions. The inlet pressure was about 1.12 bar and the mass flux was $747.5 \mathrm{~kg} / \mathrm{m}^{2} \mathrm{~s}$ for both conditions examined. The results demonstrated the strong influence of compressibility on the mode of bubble detachment and growth and therefore on flow patterns, pressure fluctuations and heat transfer rates.

The fluid mechanics of boiling in this size channel were also successfully investigated by 3-D numerical simulation for bubbles growing at a defined rate with a fixed inlet flow rate using the 3-D CFD code FLUENT 6 (no upstream compressibility). The study examined the fluid mechanics of bubble motion with heat transfer, but the mass transfer across the bubble-liquid interface was not simulated in the present work. A small vapour bubble was injected at the wall to ensure the bubble generation is under a quasi nucleation condition. Its growth was driven by an internal source of vapour, at a rate
\end{abstract}

derived by analysis of the experimental measurements of growth. The simulation reproduced well the observed motion and shape of the bubble.

The simulation was then extended to model bubbles generated and growing randomly in a 2-D channel.

\section{INTRODUCTION}

Flow boiling in assemblies of parallel channels with crosssectional dimensions of less than $1 \mathrm{~mm}$ and lengths of a few $\mathrm{cm}$ is a potential method of achieving heat removal at heat fluxes of several $\mathrm{MW} / \mathrm{m}^{2}$ with near-uniform wall temperatures, e.g. from micro-electronic devices. The channels may be machined in metal heat sinks or micro-fabricated directly into silicon chips.

The increased influence of surface tension in microchannels extends the range of occurrence of confined-bubble or slug flow, in which high heat transfer coefficients are achieved by the periodic evaporation of the thin liquid films surrounding long confined bubbles. The films are renewed by liquid from the slugs pushed along by the rapidly-expanding bubbles. Bubble growth to confinement and the subsequent acceleration of liquid slugs causes fluctuations in local pressure that may have adverse effects on performance ranging from mechanical failure of silicon assemblies to temporary flow reversals that drive vapour from one channel into another via the inlet plenum, causing transient or persistent dryout of liquid films and overheating $[1,2]$. It has been shown that flow reversal can be controlled by flow constrictions at the entry to each channel that cause a pressure drop of the same order as that across the channel $[3,4,5]$. The suppression of flow reversal does not remove the internal pressure fluctuations, which modify heat 
transfer through fluctuations in the wall superheat that controls bubble nucleation and growth. These effects are not yet included in models and associated physically-based correlations for heat transfer in confined bubble flow such as that of Thome et al.[6].

Experimental and theoretical studies of flow boiling in single micro-channels are undertaken to provide design data for multi-channel assemblies. Even single channels exhibit flow instabilities with periods ranging from hundreds of seconds (indicating interactions with the external flow and cooling circuit) to milliseconds associated with the formation of individual vapour bubbles. Flow reversal at the inlet of a single channel can only occur if there is some compressibility in the upstream external circuit, which may depend on unreported details of rig design. The pressure fluctuations and reversals may interact with the activation of bubble nucleation sites in a population that decreases as the channel size decreases, becoming more susceptible to statistical variation. These apparently secondary influences may explain some of the disagreements between experimental data for similar conditions obtained in different laboratories, as discussed in [7].

While there have been numbers of observations of flow reversals and measurements of the fluctuating pressure drop across single and parallel channels, practical problems have restricted the studies of pressure measurements within small channels linked with flow observations. Kenning and Yan, Wen et al. [8,9], Brutin and Tadrist $[10,11]$ measured pressures at tappings along single channels connected to miniature pressure transducers with high speed video recording of the bubbles in respectively water in a $2 \times 1 \mathrm{~mm}$ channel and n-pentane in a $4 \mathrm{x}$ $1 \mathrm{~mm}$ channel. They showed that the high frequency fluctuations in pressure depended on the upstream compressibility. Zhang et al. [12,13] achieved local pressure measurements for water in much smaller channels down to 0.25 $\mathrm{x} 0.1 \mathrm{~mm}$, using integrally fabricated transducers on the back of the channel that were sensitive to both temperature and pressure. This caused problems in separating the simultaneous effects of one bubble and the videos recorded at normal speed could not follow the details of individual events. Instantaneous pressures of up to 2 bar at a nominal exit pressure of 1 bar were recorded.

Numerical simulation by CFD provides an alternative method of investigating the fluctuations in pressure and heat transfer during confined bubble growth but encounters problems of its own. The accelerating growth with large inertial stresses, interfacial distortion and the formation of very thin films leads to requirements for very fine computational grids and difficulties in the accurate calculation of interfacial fluxes with commercial codes [14]. Mukherjee and Kandlikar [15,16] developed their own fully 3-D code to simulate the growth of a bubble from a nucleation site on the side wall of a rectangular channel to confinement. The channel was restricted in length and the interaction between pressure changes and evaporation was not taken into account.

This paper describes some early results from experimental and CFD studies of confined bubble growth undertaken as part of a wider investigation of boiling and condensation in microchannels by five UK Universities (Brunel, Edinburgh, HeriotWatt, Nottingham and Queen Mary, London), funded by the Engineering and Physical Sciences Research Council. Experimental observations illustrating the influence of upstream compressibility on bubble motion during growth to confinement are presented in Section 2. The observations suggest that growth may be described approximately by a very simple heat transfer model of constant heat flux through the projected bubble area in contact with the heated wall. This model is used as the basis for 3-D simulations with the commercial CFD code FLUENT 6 that avoid the calculation of local interfacial heat and mass fluxes but simulate the fluid mechanics of bubble growth to confinement. The methods of simulation are described in Section 3 and the results of simulations of a single bubble are compared with the experimental observations in Section 4. Extensions of the simulations to multiple bubbles are illustrated in Section 5.

In the accompanying paper by Gedupudi et al. [17], the 3-D simulations are used to help create a simple 1-D model that may be used for relatively rapid calculations to identify the conditions associated with large pressure fluctuations.

\section{NOMENCLATURE}

$\mathrm{A}_{1} \quad$ Bubble area, projected from top $\left(\mathrm{m}^{2}\right)$.

$\mathrm{A}_{2} \quad$ Bubble area with the projected boundary shrinked by half the channel height to account for the bubble curvature $\left(\mathrm{m}^{2}\right)$.

$c \quad$ Specific heat $(\mathrm{J} / \mathrm{kg} \mathrm{K})$

Ca Capillary number, $\mathrm{Ca}=\mu_{l} u_{l} / \sigma_{l v}$

F $\quad$ Volume fraction

g Gravitational acceleration $\left(\mathrm{m}^{2} / \mathrm{s}\right)$

$\mathrm{H} \quad$ Channel height $(0.38 \mathrm{~mm}$ for $3 \mathrm{D}$ model, $0.2 \mathrm{~mm}$ for 2D model)

$h \quad$ Heat transfer coefficient $\left(\mathrm{W} / \mathrm{m}^{2} \mathrm{~K}\right), h=q /\left(T_{w}-T_{s a t}\right)$

$\mathrm{h}_{\mathrm{lv}} \quad$ Latent heat of vaporization $(\mathrm{J} / \mathrm{kg}$ )

$k \quad$ Turbulence kinetic energy

$\mathrm{Nu} \quad$ Nusselt number, $\mathrm{Nu}=h \mathrm{H} / \lambda_{v}$

Q Heat flux ( W/m²)

Re Reynolds number, $\operatorname{Re}=\rho_{l} u H / \mu_{l}$

$T \quad$ Temperature ( $\mathrm{K}$ )

u Velocity vector

$\mathrm{u}^{*}, \mathrm{v}^{*} \quad$ Relative velocities

\section{Greek Symbols}

$\varepsilon \quad$ Turbulence dissipation rate

$\lambda$ Thermal conductivity ( $\mathrm{W} / \mathrm{mK}$ )

$\rho \quad$ Mass density $\left(\mathrm{kg} / \mathrm{m}^{3}\right)$

$\sigma \quad$ Surface tension ( N/m)

$\mu \quad$ Dynamic viscosity ( $\mathrm{Ns} / \mathrm{m}^{2}$ )

$\delta \quad$ Liquid film thickness, $\frac{\lambda_{l}}{h}(\mathrm{~m})$

$\begin{array}{ll}\text { Subscripts and Superscripts } \\ 0 & \text { averaged velocity of gas phase } \\ \text { sat } & \text { saturated } \\ l & \text { Water } \\ v & \text { Vapour } \\ w & \text { Wall }\end{array}$




\section{EXPERIMENTAL OBSERVATIONS WITH DIFFERENT UPSTREAM CONDITIONS}

The experimental rig shown schematically in figure 1 consists of a boiling vessel with an electric immersion heater to supply degassed liquid and pressurise the circuit consisting of a precooler (to keep the fluid temperatures within the limits permissible for the pump, and to avoid cavitation), a positivedisplacement gear pump, a Coriolis flow meter, an electric preheater, the test section and a condenser cooled by chilled water from a refrigeration unit, which also supplies cold water to the precooler. For these experiments, a channel of rectangular section $1.6 \times 0.38 \mathrm{~mm}$ and $40 \mathrm{~mm}$ long, was machined in a copper block with a glass window sealed to the top side by an epoxy film $30 \mu \mathrm{m}$ thick, figure 2 . The rear of the block was heated by a wire resistance heater to heat fluxes of up to $250 \mathrm{~kW} / \mathrm{m}^{2}$, averaged over the area of the three metal sides. The temperature of the block was measured by six embedded thermocouples. In future experiments the glass window will be drilled for local pressure measurements but these were not completed in time for this paper. The flow was recorded by video camera (Phantom v4.0) at 1000 frames/s.

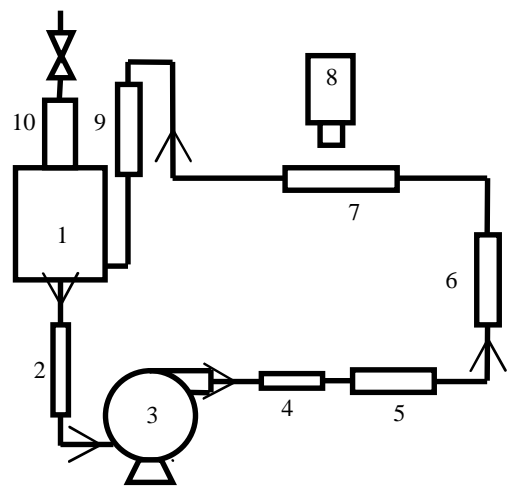

Fig. 1: Schematic of the experimental circuit.

1. Boiling vessel, 2.precooler, 3. gear pump, 4. 1-micron filter, 5. Coriolis mass flow meter, 6. preheater, 7. test-section, 8 . high-speed video camera, 9. condenser, and 10. reflux condenser for degasification.

Two designs of preheater were employed. In the first, the wall temperature at the end of the preheater was high enough to cause subcooled boiling, although bubbles were completely condensed in the adiabatic section preceding the test section. In the second design, the heating area was increased so that the wall temperature was always below the saturation temperature. In both cases, the liquid entered the test section at a subcooling degree of $7 \mathrm{~K}$. The experimental circuit was thoroughly degassed before the experiments.

Video sequences ( figure 3a) show bubble formation in the test section at $\sim 17 \mathrm{~mm}$ from the channel inlet without subcooled boiling in the preheater ("incompressible" upstream condition) for $747.5 \mathrm{~kg} / \mathrm{m}^{2} \mathrm{~s}, 210.2 \mathrm{~kW} / \mathrm{m}^{2}$, average inlet pressure $1.17 \mathrm{bar}$, and outlet pressure $1.1 \mathrm{bar}$. Bubble formation in the test section at $\sim 9 \mathrm{~mm}$ from the inlet with subcooled boiling in the preheater ("compressible" upstream condition) for $747.5 \mathrm{~kg} / \mathrm{m}^{2} \mathrm{~s}, 173.3 \mathrm{~kW} / \mathrm{m}^{2}$, average inlet pressure 1.146 bar, and outlet pressure 1.1 bar is shown in figure $3 \mathrm{~b}$. In both cases, bubbles formed regularly at particular nucleation sites. They grew rapidly to a size approximately equal to the minor dimension ( $0.38 \mathrm{~mm}$ ) of the cross-section, here termed partial confinement, then grew more slowly to complete confinement approaching the major dimension of the cross section $(1.6 \mathrm{~mm}$ ). During this second stage, there was significant movement relative to the nucleation site which was completely different for the conditions without and with upstream compressibility. Also present were other small bubbles that did not grow. These observations with a delay between nucleation and full confinement are consistent with the behaviour reported in [8]. Without inlet compressibility, figure $3 \mathrm{a}$, the bubble, which grows to full confinement in approx 5-6 ms, is pushed downstream by the oncoming liquid and develops surface irregularities. With inlet compressibility, figure $3 \mathrm{~b}$, the bubble grows from nucleation to partial confinement within then moves slightly upstream as it expands to full confinement in $\sim 10$ ms. (This may be influenced by unseen bubbles downstream). Subsequent growth is in both upstream and downstream directions. The upstream end goes out of the view at $20 \mathrm{~ms}$, and perhaps continues its growth in the upstream direction for a considerable amount of time, before returning at $47 \mathrm{~ms}$ without the convex tail that was present when it was growing in the upstream direction. The downstream end also moves out of view at $20 \mathrm{~ms}$. Some stationary irregularities in the bubble shape may be due to small bubbles attached to the window by surface tension.

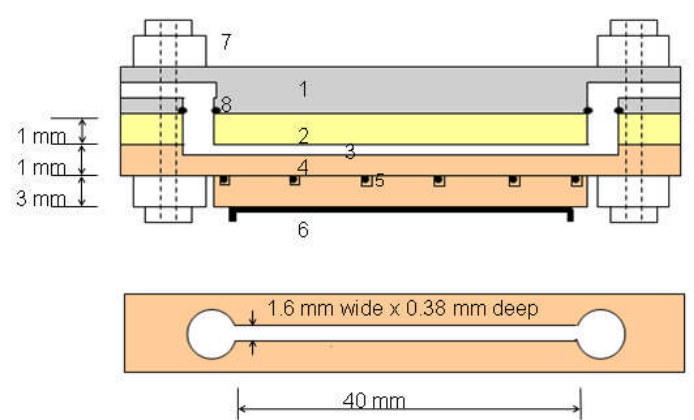

Fig. 2: Schematic of the test section. 1. polycarbonate, 2. pyrex glass, 3. microchannel, 4. copper substrate, 5.thermocuple, 6 . heater, 7. clamp, 8. O-ring.

Figures $4 \mathrm{a}$ and $4 \mathrm{~b}$ show the bubble projected area versus time without and with inlet compressibility respectively. The almost linear nature of the graphs with area on a logarithmic scale indicates exponential growth, which is the basis for the model developed in the accompanying paper [17]. The data show the areas of 8 sequential images of different bubbles just before the they go out of view, obtained by tracing the images. In figure $4 \mathrm{a}$, the data for the three bubbles lie close to a single straight line, except for the first two points for bubble 3 . In figure $4 \mathrm{~b}$, the data follow two straight lines of different slope (different exponential time constant) after the first $2 \mathrm{~ms}$. At very early times, the measurements of projected area are less accurate and growth may be influenced by dry areas under the nearly stationary bubbles and disturbances from other bubbles.

Assuming that heat is transferred to the bubble only through the contact area with the heated wall, the heat transfer coefficient at any time $t$ is given by 


$$
h(t)=\frac{\rho_{v} h_{l v} H \frac{d A_{1}}{d t}}{A_{1}\left(T_{w}-T_{\text {sat }}\right)}
$$

and the liquid film thickness is estimated by

$$
\delta=\frac{\lambda_{l}}{h}
$$

Here $A_{1}$ is the projected area of the bubble, and $H$ is the channel depth. Heat transfer through the side walls is neglected.

To account for the curvature of the bubble edges, area $A_{2}$ was obtained by shrinking the bubble boundary by $0.2 \mathrm{~mm}$ (approximately equal to half the channel depth )

The corresponding heat transfer coefficient is given by

$$
h^{\prime}=\frac{\rho_{v} h_{l v} H \frac{1}{2} \frac{d\left(A_{1}+A_{2}\right)}{d t}}{A_{2}\left(T_{w}-T_{s a t}\right)}
$$

For case 'a' ( without inlet compressibility), the arithmetic average values of $h$ and $\delta$ are approximately $19.1 \mathrm{~kW} / \mathrm{m}^{2} \mathrm{~K}$ and 28 to $40 \mu \mathrm{m}$ respectively, while $h^{\prime}$ and $\delta^{\prime}$ are approximately $35.3 \mathrm{~kW} / \mathrm{m}^{2} \mathrm{~K}$ and 12 to $23 \mu \mathrm{m}$ respectively.

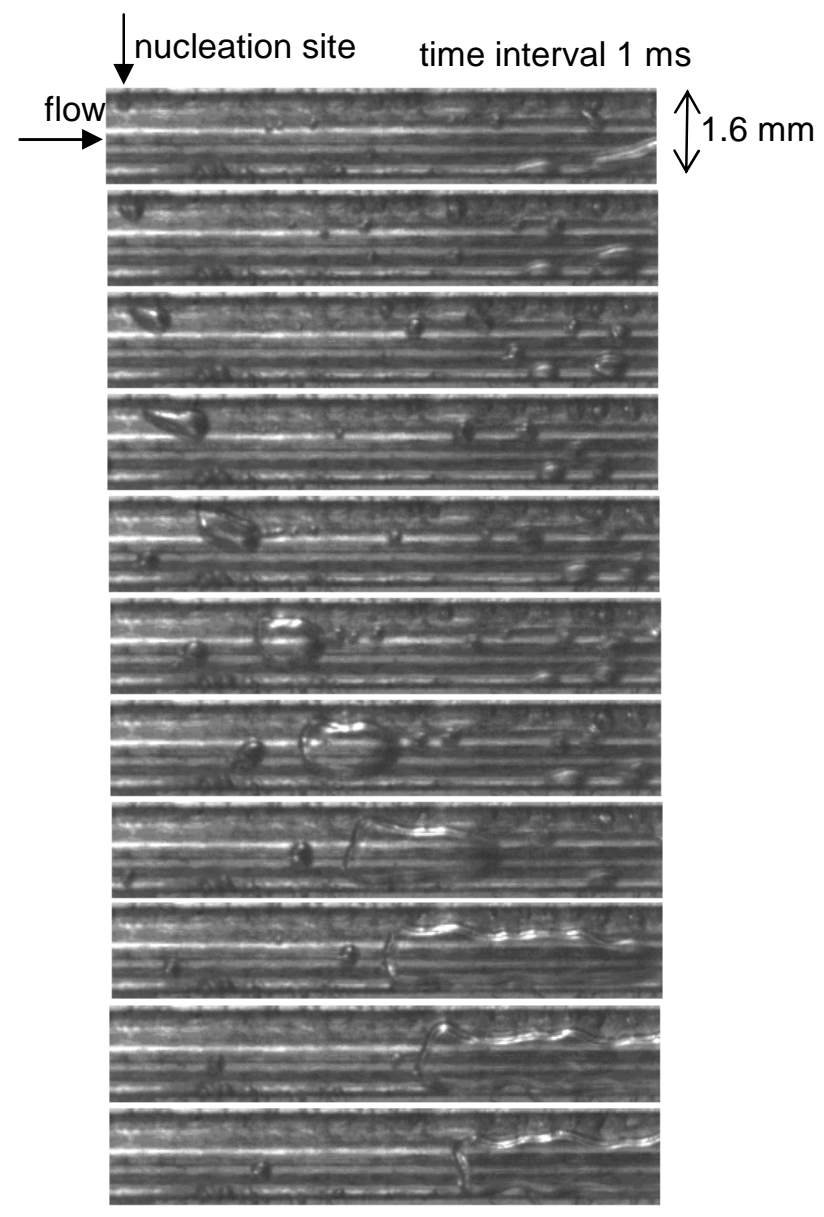

a: without inlet compressibility.

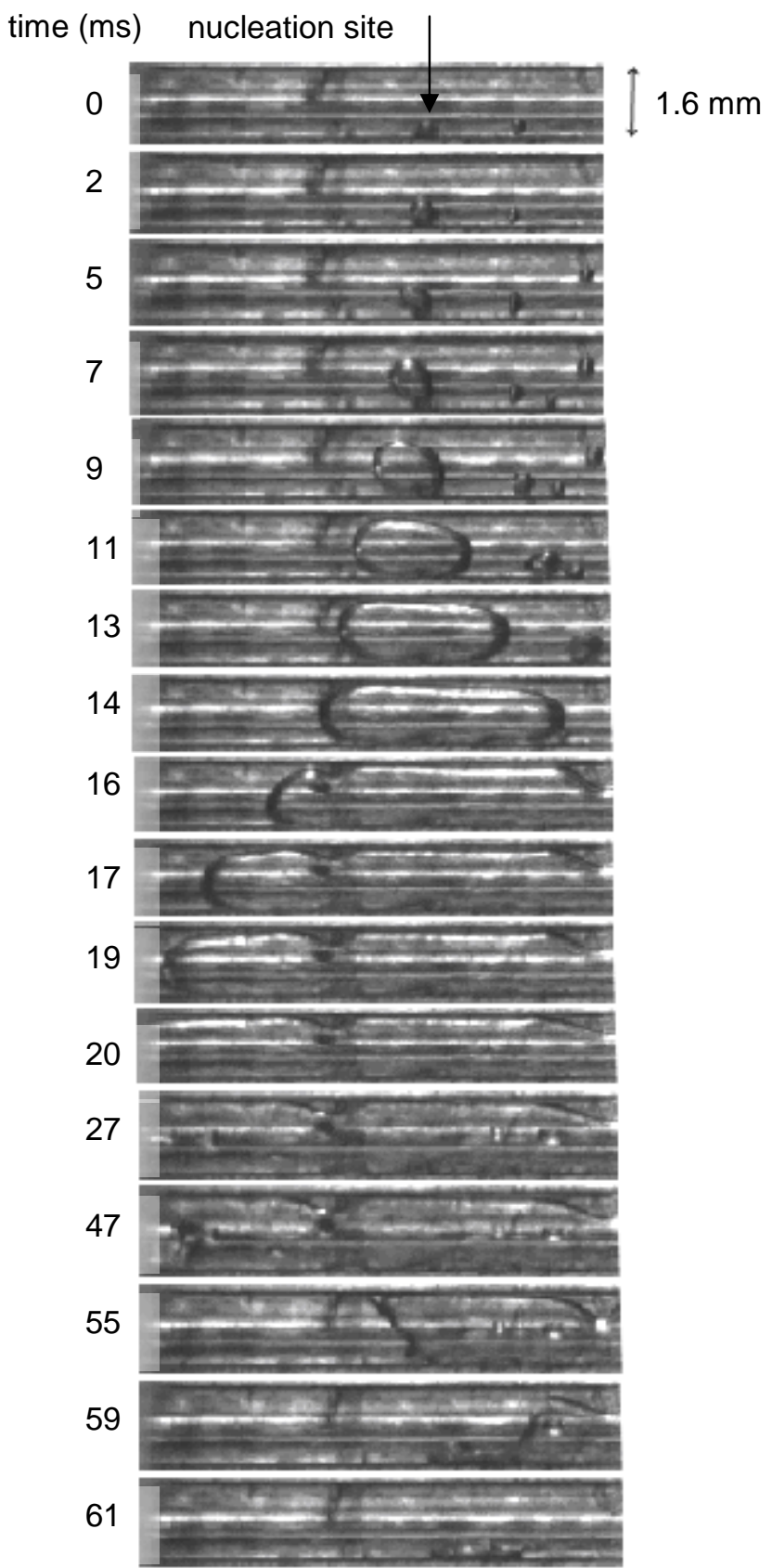

b: with inlet compressibility.

Fig. 3: Video sequences of the bubble growth and movement.

For case 'b' (with inlet compressibility), the average values of $h$ and $\delta$ are approximately $25.6 \mathrm{~kW} / \mathrm{m}^{2} \mathrm{~K}$ and 21 to $33 \mu \mathrm{m}$ respectively, while $h^{\prime}$ and $\delta^{\prime}$ are approximately $49 \mathrm{~kW} / \mathrm{m}^{2} \mathrm{~K}$ and 10 to $18 \mu \mathrm{m}$ respectively.

In case ' $\mathrm{a}$ ' (without inlet compressibility), there was regular nucleation with a period of $12-13 \mathrm{~ms}$, similar to the time of $10-11$ ms estimated, by extrapolation of the growth rate, for the downstream end of the bubble to reach the channel outlet. This may indicate the possibility that the nucleation is triggered by the transient pressure reduction throughout the 
length of the channel (decreasing saturation temperature and increasing wall superheat) as the bubble approaches the channel outlet.
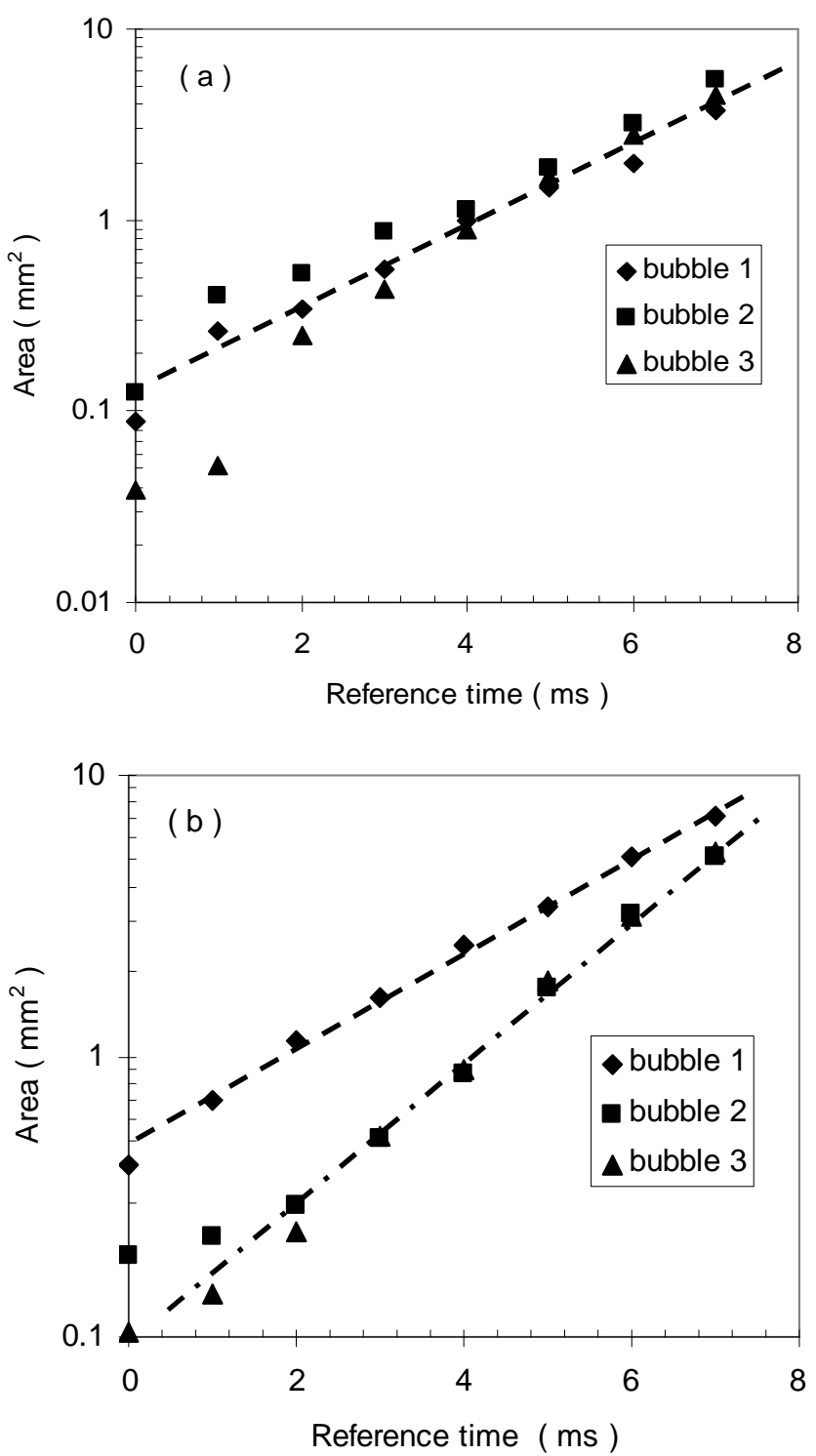

Fig. 4: Projected bubble area versus time. (a) without inlet compressibility. (b) with inlet compressibility.

\section{3-D NUMERICAL SIMULATION}

Bubbles are generated by injecting a small vapour bubble through an inlet located on the heated wall, which acts as the nucleation centre, in order to generate a nucleate effect or quasi-nucleation condition. Transient vapour mass flow, based on bubble growth period before detachment and departure volume obtained by the present experiments, was applied to approximate the bubble growth.

\section{The VOF method}

The volume of fluid (VOF) method [18] was used to track a scalar field variable $F$, namely volume fraction, which stands for the distribution of the second fluid in the computational grid. $F$ takes a value between 0 and 1 for the cell containing interface and a value of 0 or 1 for the cell occupied by pure vapour or water, correspondingly. The definition of the Ffunction is given by

$$
\left\{\begin{array}{ccc}
F=0 & \cdots & \text { Vapour phase } \\
0<F<1 & \cdots & \text { Interface } \\
F=1 & \cdots & \text { Water phase }
\end{array}\right.
$$

In the VOF method, the velocity field $\mathbf{u}$ and the distribution of volume fraction $F$ are coupled to satisfy the following transport equation:

$$
\frac{\partial F}{\partial t}+\nabla \cdot(\mathbf{u} F)=0
$$

Eq. (5) is solved together with the fundamental equations of conservation of mass, momentum and energy to achieve computational coupling among the velocity field, temperature field and the phase distribution. The distribution of volume fraction has to be reconstructed at every time step. Meanwhile, the distribution of fluid properties is updated based on the properties at the interface represented as:

$$
\begin{array}{ll}
\rho=\rho_{l} F+\rho_{v}(1-F) ; & \mu=\mu_{l} F+\mu_{v}(1-F) ; \\
\lambda=\lambda_{l} F+\lambda_{v}(1-F) ; & c=c_{l} F+c_{v}(1-F) .
\end{array}
$$

\section{Turbulence Model}

In the present simulation, the standard $k-\varepsilon$ model [19] was used to solve the equation of momentum. During the simulation, the channel inlet boundary condition and initial conditions are laminar and this was arranged by setting both turbulence kinetic energy and turbulence dissipation rate at the initial and boundary conditions to zero. However, the turbulence model must be used to prepare for the potential turbulence caused by the high vapour velocity during the bubble generation and growth.

Default parameters in the $k-\varepsilon$ transport equations defined in the FLUENT code [20] have been found to work fairly well for a wide range of wall-bounded and free shear flows and therefore are used in the present simulation.

\section{Geometry and Boundary Conditions}

Figure 5 shows the computational domain in which hot water with uniform velocity enters a rectangular $(0.38 \mathrm{~mm} \times 1.6$ $\mathrm{mm}$ ) channel of $40 \mathrm{~mm}$ length, which is heated on the bottom and side walls with constant heat flux of $210.2 \mathrm{~kW} / \mathrm{m}^{2}$. The top wall of the channel is adiabatic. As mentioned above, to simulate the nucleation conditions and its effect, bubbles are generated by numerically injecting small vapour bubbles through a circular inlet with a diameter of $0.2 \mathrm{~mm}$ located on the side heated wall at $x=10 \mathrm{~mm}$. Meanwhile transient vapour mass flow, based on the rate of bubble growth shown in the experiments, is applied to approximate the bubble growth.

During the simulation, hot water at constant temperature of $369.95 \mathrm{~K}$ enters the channel at a mass flux of $747.5 \mathrm{~kg} / \mathrm{m}^{2} \mathrm{~s}$, bubbles are generated at $388.65 \mathrm{~K}$ (experimental wall temperature), all as per the experimental data. Table 1 shows the physical parameters of water and vapour at saturation temperature $(373.15 \mathrm{~K})$ employed in the present simulation. 


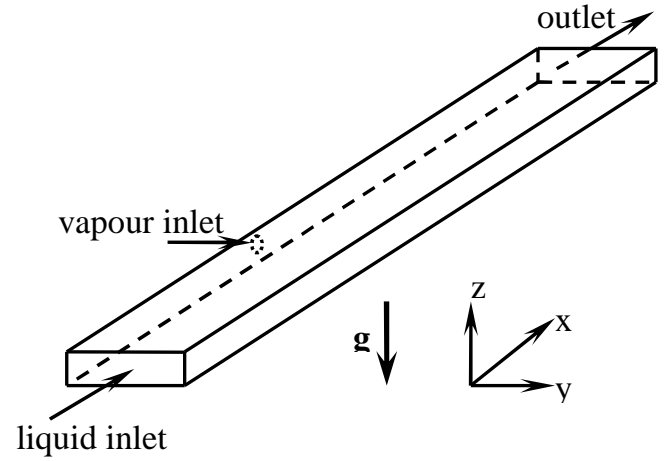

Fig. 5: Computational domain

\begin{tabular}{|c|l|c|l}
$\sigma_{l v}$ & $5.89 \times 10^{-2} \mathrm{~N} / \mathrm{m}$ & $c_{v}$ & $2028.1 \mathrm{~J} / \mathrm{kgK}$ \\
$g$ & $9.81 \mathrm{~m} / \mathrm{s}^{2}$ & $\rho_{l}$ & $987 \mathrm{~kg} / \mathrm{m}^{3}$ \\
$\lambda_{l}$ & $0.68 \mathrm{~W} / \mathrm{mK}$ & $\rho_{v}$ & $0.596 \mathrm{~kg} / \mathrm{m}^{3}$ \\
$\lambda_{v}$ & $2.48 \times 10^{-2} \mathrm{~W} / \mathrm{mK}$ & $\mu_{l}$ & $2.79 \times 10^{-4} \mathrm{~kg} / \mathrm{ms}$ \\
$c_{l}$ & $4217 \mathrm{~J} / \mathrm{kgK}$ & $\mu_{v}$ & $1.2023 \times 10^{-5} \mathrm{~kg} / \mathrm{ms}$
\end{tabular}

Table 1: Material parameters used in the simulations

\section{Analysis of Grid Sensitivity}

Non-uniform hexahedral elements $225 \times 50 \times 20$ are used for meshing the channel. The mesh near the nucleation centre was refined so that the circular boundary of the nucleation centre occupies 80 grid points. By doing this, the vapour-liquid interface can be smooth enough at the initial evolution of flow field. A grid sensitivity study was firstly performed for the early stages of development of the flow. It was found that the local heat transfer coefficient, when $\mathrm{t}=1.0 \mathrm{~ms}$, on the heated wall and the local velocity at cross-section of $\mathrm{z}=0.19 \mathrm{~mm}$ change less than $0.12 \%$ and $0.18 \%$ respectively when the grid size was changed from $225 \times 50 \times 20$ to $450 \times 100 \times 40$. To save the computational resources, the mesh of $225 \times 50 \times 20$ was used for these simulations.

\section{COMPARISON OF SIMULATION WITH EXPERIMENT}

A preliminary steady-state single phase simulation was performed to provide the initial conditions of the transient VOF simulation. The vapour inlet zone is temporarily set as a wall with the temperature consistent of the channel bottom surface in order to obtain initial solutions of steady-state. The solutions may be pursued until all residuals drop below $1 \times 10^{-6}$.

To simulate the bubble movement and heat transfer rate with time, the implicit and unsteady solver with double precision was used for the solution of the system of governing equations. The momentum and energy equations were discretized using the second-order upwind scheme; pressure equation by Body Force Weighted scheme; and the equation of volume fraction by the Geo-Reconstruct scheme. The discretized equations were solved using the PISO algorithm [20]. The time step size was set at $1 \times 10^{-6} \mathrm{~s}$. At each time step, the solution was assumed to converge when the normalized residual of the energy equation was lower than $10^{-6}$ and the normalized residuals of the continuity and all other variables are less than $10^{-3}$. In addition, the maximum iterations per time step was set at 20. The computation cost was about 9.6 seconds per time-step on a Xeon $3.2 \mathrm{GHz}$ PC machine with $3.00 \mathrm{~GB}$ of RAM.

The numerical results were first compared with the experimental data obtained at Brunel University in order to validate the reliability and accuracy of the proposed strategy, see in figure 6. The bubble growth before detaching form the nucleation centre was simulated by injecting small vapour bubbles with a mass flow rate of $2.35 \times 10^{-8} \mathrm{~kg} / \mathrm{s}$, which is obtained on the basis of bubble growth shown in the experiments, before $\mathrm{t}=3.9 \mathrm{~ms}$. After that, the bubble detaches from the nucleation site. The comparison in figures 6 and 7 shows that the development with time of the interface shapes obtained by the present numerical method agree well with those of the experiments and indicates that the present method can be applied to simulate a reliable evolution of bubble growth and movement during nucleate flow boiling.

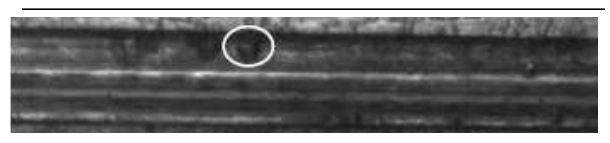

(a) $\mathrm{t}=1.1 \mathrm{~ms}$

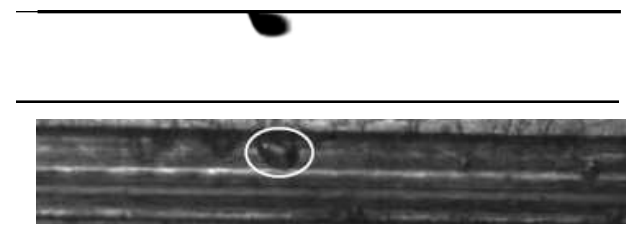

(b) $\mathrm{t}=2.8 \mathrm{~ms}$

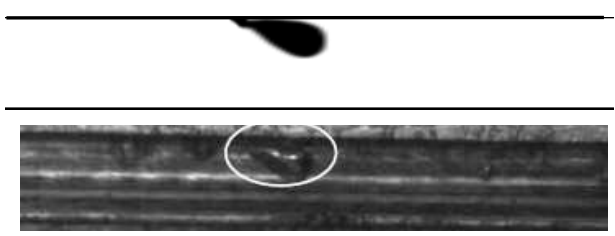

(c) $\mathrm{t}=3.9 \mathrm{~ms}$

Fig. 6: Evolution of bubble shapes

(Upper: numerical results; Lower: Experimental results)

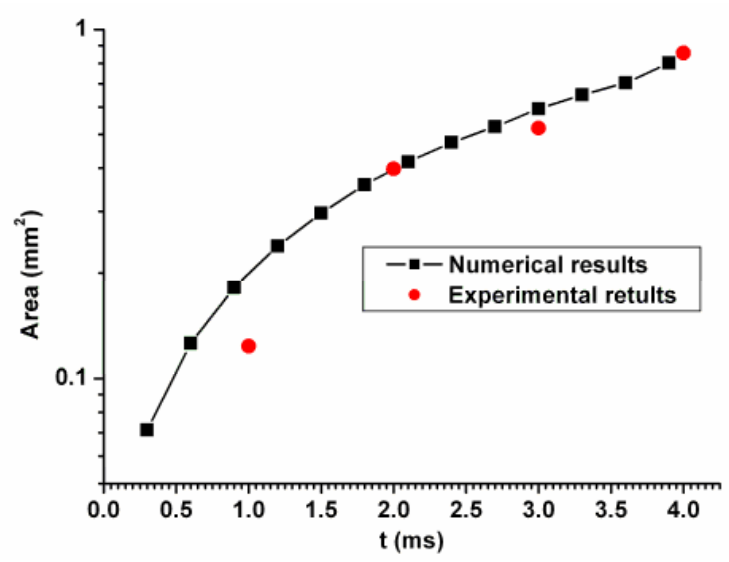

Fig. 7: Project area of bubble in z-direction 
Evolution of the velocity field was obtained by the simulation as well and is depicted in figures 8 and by pathlines and vorticity contours. The corresponding pressure field at the cross section of $\mathrm{z}=0.19 \mathrm{~mm}$ is shown in figure 10 . The gray areas and lines show the location of the liquid-vapour interface. When single-phase fluid flows in the channel, the direction of the velocity should be parallel with the $\mathrm{x}$-axis everywhere. Therefore, from figure 8 , it can be seen that bubble generation, growth and movement downstream can change the direction of fluid flow, which may cause the generation of the vortices near the bubble, as shown in the figure 9 for the vorticity contours at the cross-section of $\mathrm{z}=0.005 \mathrm{~mm}$ and therefore enhance the heat transfer rates.

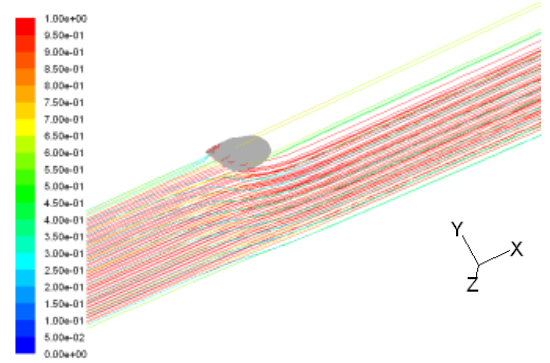

(a) $\mathrm{t}=2.8 \mathrm{~ms}$

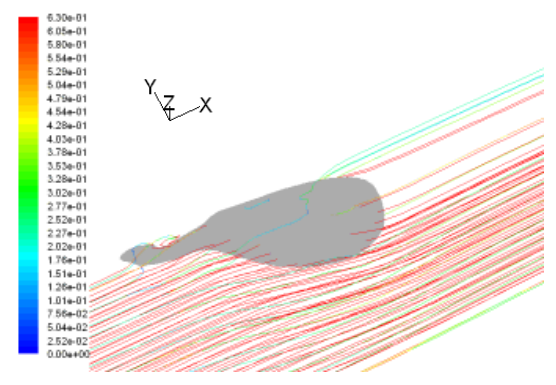

(b) $\mathrm{t}=3.9 \mathrm{~ms}$

Fig. 8: Pathlines colorized by velocity magnitude $(\mathrm{m} / \mathrm{s})$

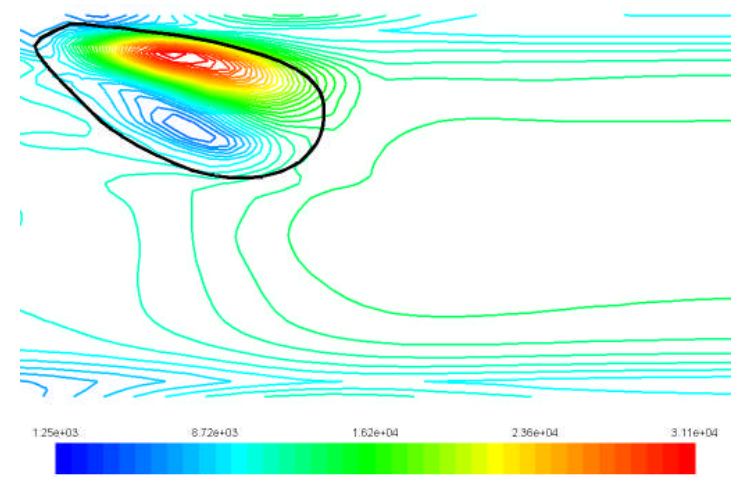

Fig. 9: contours of vorticity magnitude (1/s)

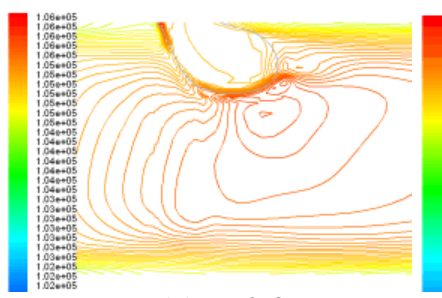

(a) $\mathrm{t}=2.8 \mathrm{~ms}$

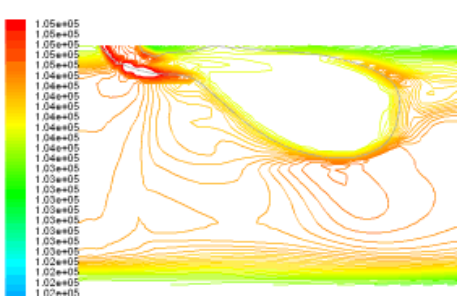

(b)t $=3.9 \mathrm{~ms}$
Fig. 10: Distribution of total pressure $(\mathrm{Pa})$.

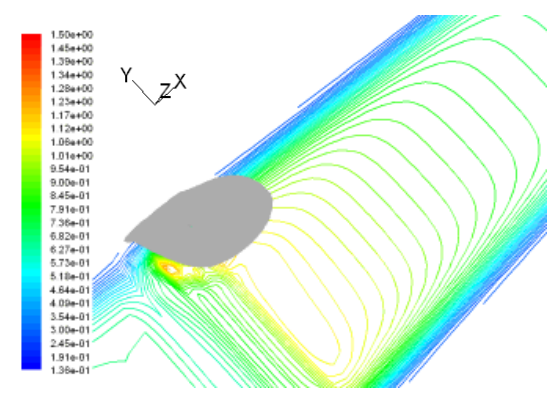

(a) $\mathrm{t}=2.8 \mathrm{~ms}$

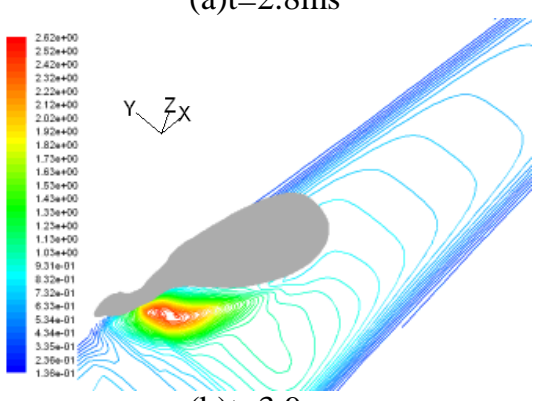

(b)t $=3.9 \mathrm{~ms}$

Fig. 11: Distribution of Nusselt number on the bottom wall.

The local Nusselt number was calculated based on the heat flux on the wall. The distribution of Nusselt number at the bottom wall and the corresponding bubble location are shown in figure 11 to evaluate further the effects of bubble motion on heat transfer. The figures show that there is a region with higher heat transfer rates near the upstream of the bubble. As mentioned above, it could be the result of generated vortices there. In the confined narrow channel, the bubble may grow in volume and reach the top and bottom walls. As a result, the velocity of the bubble can be decreased by the shear stress at the walls. At this time, a relative cross flow of liquid past the bubble takes place and generates the vortices near the interface.

\section{EXTENSIONS OF SIMULATION}

In nucleate flow boiling, there may be random generation of bubbles from several nucleation sites. Therefore, a 2-D case with random bubble generation is presented in this section. The details of velocity and temperature distributions in the channel during nucleate boiling, which are difficult to be obtained by experiments are presented and discussed. Bubbles flow and heat transfer rates in a rectangular channel, as shown in figure 11 , were studied. Water enters the channel $(0.2 \mathrm{~mm} \times 30 \mathrm{~mm})$ at an inlet Reynolds number of 141.5 , a capillary number of 
$9.47 \times 10^{-4}$, and a pressure of 1 bar. In this case, the bubbles are generated with random frequency at a fixed location which is $10 \mathrm{~mm}$ away from the channel entrance, to avoid the entrance effects. A constant temperature of $383.15 \mathrm{~K}$, which is $10 \mathrm{~K}$ higher than the saturated water temperature, is specified at the bottom surface of the channel, while the top wall of the channel is adiabatic.

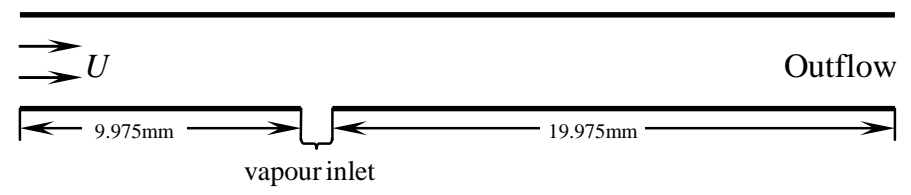

Fig. 12: Computational domain

Figure 13 shows the detailed view of the bubble distribution and the corresponding streamlines in the channel when $\mathrm{t}=3 \mathrm{~ms}$. Here, the streamlines are based on the relative velocity $\left(\mathrm{u}^{*}, \mathrm{v}^{*}\right)$ given by

$$
\mathrm{u}^{*}=\mathrm{u}-\mathrm{u}_{0} ; \mathrm{v}^{*}=\mathrm{v}-\mathrm{v}_{0}
$$

where, $\mathrm{u}$ and $\mathrm{v}$ are the horizontal and vertical components of the absolute velocity, and $\left(\mathrm{u}_{0}, \mathrm{v}_{0}\right)$ are the averaged velocity of gas phase.

In traditional channels, the bubble deformation in bubbly flows is caused by the combined action of buoyancy and surface tension forces which are comparable. As a result, some interesting bubble shapes including the mushroom shape can appear. In mini- or micro- channels, since the surface tension dominates the flow the shape of each bubble downstream is nearly symmetrical with respect to the horizontal centreline of the channel. Moreover, due to the narrow channel height, which can be smaller than the bubble diameter, the water between two adjacent bubbles is nearly always encaged in the cavity formed by the channel walls and two bubble-water interfaces, and therefore the probability of bubble coalescence can be lower.

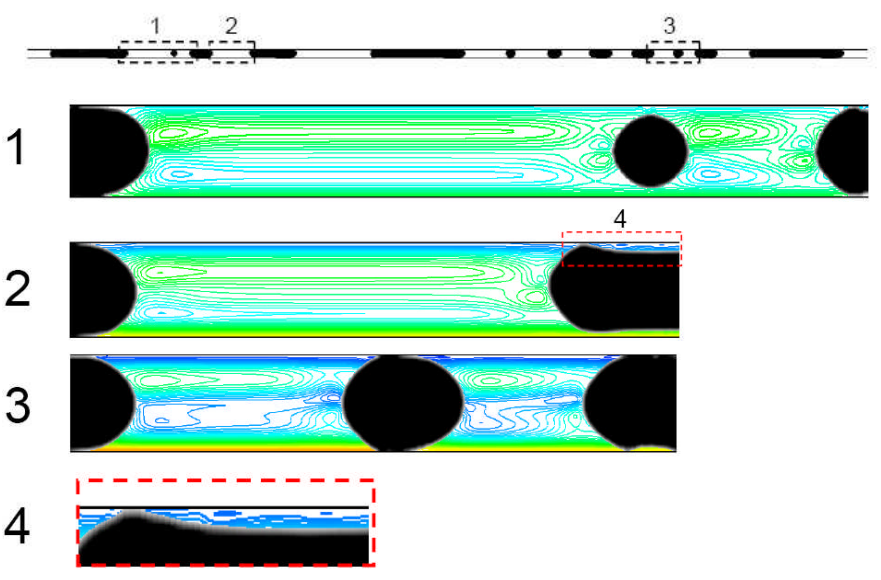

Fig. 13: Distribution of bubbles and the corresponding streamlines in 2D channel

Moreover, from the streamline plots of figure 14, it can be seen that the vortices are generated at the front and rear of the vapour bubbles, which may enhance the heat transfer rates. The enlarged view of zone 4 demonstrates that thin liquid layer with an approximate thickness of $3 \sim 15 \mu \mathrm{m}$ exists within the narrow gap between the elongated bubbles and the channel walls. Some small vortices are also generated in the thin liquid layer.

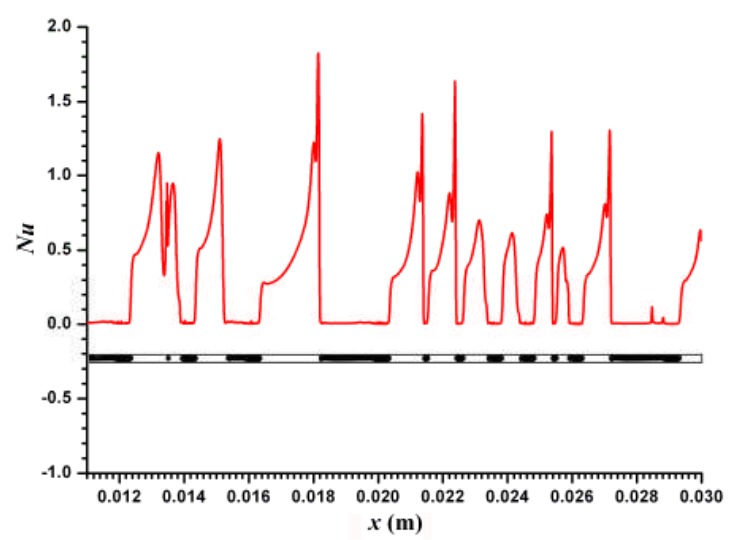

Fig. 14: Bubble positions and the corresponding distribution of local Nusselt number on the heated wall at $\mathrm{t}=3 \mathrm{~ms}$.

Bubble position and the corresponding distributions of the local Nusselt number along the heated wall at $\mathrm{t}=3 \mathrm{~ms}$ are given in figure 14 to study the relationship between the heat transfer and the transient bubble locations. It can be seen that there are some regions of relative lower local Nusselt number. These correspond to the vapour-wall interface. This could be caused by the relatively low temperature differences between the vapour and the wall.

\section{CONCLUSIONS}

Experiments have demonstrated the large influence of apparently small changes in upstream conditions on the growth of confined bubbles in flow boiling experiments in single channels. Video images of the observed nucleation, partiallyconfined and fully-confined bubble growth were presented. Rough estimates of the heat transfer coefficient and the liquid film thickness underneath the growing bubble were also made. The video observations showed that bubbles detaching from a wall nucleation site and growing towards full confinement moved downstream only if rigorous precautions were taken to eliminate compressibility due to bubbles in the pipework and preheater between the positive-displacement pump and the test section. An apparently minor difference in rig design leading to subcooled boiling near the end of the preheater caused a major change in the mode of bubble detachment and growth, so that bubbles grew upstream as well as downstream, preventing fresh liquid from entering the region of observation for long periods. Unrecorded external influences of this sort may explain some of the disagreement between experimental measurements of flow boiling heat transfer coefficients performed in different laboratories for apparently similar conditions.

Bubble generation and growth was simulated by injecting a small vapour bubble at intervals through an inlet located on the heated wall which then acts as the nucleation centre. Meanwhile a transient vapour mass flow, based on the boiling parameters, was included to approximate the bubble growth. The experimental validation indicates that the present method can give reliable evolution of the bubble movement during the nucleate boiling.

The numerical simulation demonstrated that in the confined narrow channel, the bubble may grow in volume and attach to 
the top and bottom walls. As a result, the velocity of the bubble can be decreased by the shear stress at the walls. At this time, a relative cross flow of liquid past bubble takes place and generates vortices near the interface. Such vortices may enhance the local heat transfer rates.

A subsequent 2-D simulation showed that vortices are generated around the vapour bubbles. A thin liquid layer exists within the narrow gap between the elongated bubbles and the channel walls, with some small vortices generated in this thin liquid layer.

Other computed features of the flow were used to validate a simple 1-D model for the pressure changes during confined growth, as described in an accompanying paper by the same authors. This work is part of the development of models for pressure fluctuations and flow reversals in parallel channels.

\section{ACKNOWLEDGEMENT}

The work is supported by the UK Engineering and Physical Sciences Research Council (EPSRC) under grants EP/D500095/1 and EP/D500125/1.

\section{REFERENCES}

1. K. Cornwell and P.A. Kew, Boiling in small parallel channels, in P.A. Pilavachi (ed.), Energy Efficiency in Process Technology, pp. 624-638, Elsevier, NY, 1993.

2. A.E. Bergles and S.G. Kandlikar,On the nature of critical heat flux in microchannels, J. Heat Transfer, vol. 127, pp. 101-107, 2005.

3. S.G. Kandlikar, W.K. Kuan, D.A. Willistein and J. Borrelli, Stabilization of flow boiling in microchannels using pressure drop elements and fabricated nucleation sites, J. Heat Transfer, vol. 128, pp. 389-396, 2006.

4. A. Koşar, C. J. Kuo and Y. Peles, Suppression of boiling flow oscillations in parallel microchannels by inlet restrictions, J. Heat Transfer, vol. 128, pp. 251-260, 2006.

5. P.C. Lee and C. Pan, Boiling heat transfer and two-phase flow of water in a single shallow microchannel with a uniform or diverging cross-section, J. Micromech. Microengineering, vol. 18, 025005, 2008.

6. J.R. Thome, V. Dupont and A.M. Jacobi, Heat transfer model for evaporation in microchannels, Part I: Presentation of the model, Int. J. Heat Mass Transfer, vol. 47, pp. 3375-3385, 2004.

7. T.G. Karayiannis, D. Shiferaw and D.B.R. Kenning, Saturated flow boiling in small- to micro-diameter metallic tubes: experimental results and modelling, ECI International Conference on Heat Transfer and Fluid Flow in Microscale, Whistler, 21-26 September 2008.

8. D.B.R. Kenning and Y. Yan, Saturated flow boiling of water in a narrow channel: experimental investigation of local phenomena, IChemE Trans. A, Chem. Eng. Research and Design, vol. 79, pp. 425-436, 2001.

9. D.S. Wen, D.B.R. Kenning and Y. Yan, Flow boiling of water in a narrow vertical channel at low mass flux: observations of local phenomena, Proc.12th Int.Heat Transfer Conf. Grenoble, vol. 3, pp. 773-778, 2002.

10. D. Brutin, F. Topin and L. Tadrist, Experimental study of the unsteady convective boiling in heated minichannels, Int. J. Heat Transfer, vol.46, pp. 2957-2965, 2003.

11. D. Brutin and L. Tadrist, Pressure drop and heat transfer analysis of flow boiling in a minichannel; influence of the inlet condition on two-phase flow stability, Int. J. Heat Mass Transfer, Vol.47, pp. 2365-2377, 2004.

12. L. Zhang, K.E. Goodson and T.W. Kenny, Silicon Microchannel Heat Sinks, Theories and Phenomena, Springer Verlag, Berlin, Heidelberg, New York, 2003.

13. L. Zhang, E.N. Wang, K.E. Goodson and T.W. Kenny, Phase change phenomena in silicon microchannels, Int. J. Heat Mass Transfer, vol. 48, pp.1572-1582, 2005.

14. D.B.R. Kenning, D.S. Wen, K.S. Das, and S.K. Wilson, Confined growth of a vapour bubble in a capillary tube at initially uniform superheat: experiments and modelling, Int. J. Heat Mass Transfer, vol. 49, pp. 4653-4671, 2006.

15. A. Mukherjee and Satish G. Kandlikar, Numerical simulation of growth of a vapour bubble during flow boiling of water in a microchannel, Microfluid Nanofluid vol. 1, pp. 137-145, 2005.

16. A. Mukherjee and Satish G. Kandlikar, Numerical study of the effect of inlet constriction on bubble growth during flow boiling in microchannels, 3rd International Conference on Microchannels and Minichannels, ICMM2005-75143, Toronto, Ontario, Canada, 2005.

17. S.Gedupudi, Y.Q. Zu, T.G. Karayiannis, D.B.R. Kenning, Y.Y Yan, 1-D modelling and 3-D simulation of confined bubble formation and pressure fluctuations during flow boiling in a mini-micro channel with a rectangular crosssection of high aspect ratio, ICNMM2009-82119.

18. C.W. Hirt, B.D Nichols, Volume of fluids (VOF) method for the dynamics of free boundaries, J. Comput. Phys, vol. 39, pp. 201$225,1981$.

19. B.E. Launder and D.B. Spalding, Lectures in Mathematical Models of Turbulence. Academic Press, London, England, 1972.

20. FLUENT 6.1 Documentation, FLUENT Inc., 2003.

21. Y.Q. Zu, Y.Y. Yan, A numerical study of quasi-nucleate boiling in mini- and micro channels, 6th International Conference on Microchannels and Minichannels, ICNMM2008-62112, Darmstadt, Germany, 2005. 